\title{
Vegetative Compatibility and Seasonal Variation Among Isolates of Sclerotinia homoeocarpa
}

\author{
J. F. Powell, Department of Plant Pathology, University of Minnesota, St. Paul 55108, and J. M. Vargas, Jr., De- \\ partment of Botany and Plant Pathology, Michigan State University, East Lansing 48824
}

\begin{abstract}
Powell, J. F., and Vargas, J. M., Jr. 2001. Vegetative compatibility and seasonal variation among isolates of Sclerotinia homoeocarpa. Plant Dis. 85:377-381.

Dollar spot of amenity turf, caused by Sclerotinia homoeocarpa, occurs in two seasonal epidemics in the northern United States, one from May to late July and a second from mid-August through October. It is not known whether these seasonal epidemics are the result of multiple species or due to seasonal variation within a single species. Isolates of $S$. homoeocarpa were collected from dollar spot lesions obtained from golf courses in Michigan, Illinois, and Wisconsin. Vegetative compatibility reactions between isolates identified six vegetative compatibility groups (VCGs) among more than 1,300 isolates collected from the eight locations. Most VCGs were present throughout the season, but one was generally recovered only in the late epidemic. Sequences of the nuclear ribosomal internal transcribed spacer 1 (ITS1) were identical among VCGs, indicating that the VCGs represent a single species. The results of this study suggest that the seasonal dollar spot epidemics observed in the northern United States are caused by a single species.
\end{abstract}

Dollar spot is one of the most prevalent diseases of turfgrasses throughout the world, occurring on a broad range of warm and cool season grasses (23). It is also the most economically important disease of turf in the United States and Canada $(9,27)$. On golf course putting greens and fairways, dollar spot appears as bleached to tan spots up to $5 \mathrm{~cm}$ in diameter. Under favorable conditions, the spots will coalesce to form larger irregular patches. When occurring on taller turfs (home lawns, athletic turf, etc.), spots may reach $15 \mathrm{~cm}$ in diameter. Dollar spot incidence is favored by high humidity, temperatures from 15 to $25^{\circ} \mathrm{C}$, and cool nights resulting in dew formation. Following nights of heavy dew formation, white fuzzy "cobwebs" of mycelium may be seen on infected turf. Infected leaves initially appear chlorotic and water-soaked, becoming bleached or straw colored. Lesions are often delineated from healthy tissue by the presence of a dark brown to black border. The organism is believed to spread through the movement of mycelia and infected clippings, as the causal fungus is not known to produce conidia or reproduce sexually in the United States. Management of dollar spot is commonly attained through the use of fungicides. This organ-

Corresponding author: J. F. Powell

E-mail: jpowell@puccini.crl.umn.edu

Accepted for publication 3 December 2000

Publication no. D-2001-0125-01R

(C) 2001 The American Phytopathological Society ism has developed resistant populations to numerous fungicides, including the benzimidazoles (28), dicarboxamides (5), and demethylase inhibitors (8). Cultural practices employed to manage dollar spot include maintenance of high nitrogen fertility (20), removal of dew (30), and maintenance of proper irrigation (4).

The pathogen responsible for dollar spot is currently identified as Sclerotinia homoeocarpa F.T. Bennett (2). However, inclusion of this pathogen in the genus Sclerotinia has been refuted based on examinations of apothecial anatomy (11), stromatal anatomy, stromatal histochemistry $(16,22)$, and nuclear ribosomal internal transcribed spacer region 1 sequence data (3). The pathogen identified as S. homoeocarpa is currently believed to belong to either the genus Lanzia, Moellerodiscus, or Rutstroemia (3). It has been suggested that dollar spot may not be caused by a single species, but rather by multiple species, or by a complex of species $(11,14,24)$.

Dollar spot in cool season climates occurs during two seasonal epidemics in most years, with one epidemic in the spring to early summer (May to July) and a later epidemic in the late summer through fall (mid-August to October) (25). Little is understood about the underlying population dynamics of the dollar spot pathogen during these two seasonal epidemics. Questions remain whether these seasonal epidemics are caused by the same species, by different subpopulations of a single species, or by multiple species.

In one of the few studies of S. homoeocarpa populations, Sonoda (25) identified 54 vegetative compatibility groups (VCGs) among 119 isolates collected from three locations in central Florida. Vegetative compatibility is the ability of hyphae of two strains of fungi to fuse and form a stable heterokaryon. In order for the strains to form a stable heterokaryon, they must share identical alleles at a particular set of loci. Strains that differ at any of these loci will not be able to form a stable heterokaryon and will result in an incompatible reaction typified by death of the heterokaryotic cells (19). Among asexual fungi (including $S$. homoeocarpa), VCGs represent genetically isolated subpopulations, and members of the same VCG are generally more similar than members of different VCGs $(6,10,13,17,26)$.

The objectives of this study were to examine the occurrence of vegetative compatibility groups among $S$. homoeocarpa in Michigan and determine if seasonal epidemics of dollar spot in Michigan are caused by a single species, different populations within a single species, or multiple species.

\section{MATERIALS AND METHODS}

Sampling. Investigation into variation of $S$. homoeocarpa populations that cause early and late summer epidemics of dollar spot was conducted by collecting isolates at regular intervals throughout the season at the Hancock Turfgrass Research Center (HTRC; Michigan State University, East Lansing). Isolates were collected every 3 weeks in 1995 (16 June through 20 September; 194 isolates in total) and 1996 (12 June through 21 September; 206 isolates in total), and every 2 weeks in 1997 (26 June through 18 September; 271 isolates in total). Infected blades from dollar spots were collected every $3 \mathrm{~m}$ along a transect across creeping bentgrass (Agrostis palustris Huds.) and annual bluegrass (Poa annua L.) plots. The number of isolates collected at each of the collection dates is provided in Table 1.

S. homoeocarpa isolates were collected once in the early summer and again in the fall of 1996 and 1997 from golf courses in northern Illinois and Lenawee County in southern Michigan. Samples collected from the Illinois site were taken from a single fairway at 3-m intervals, and isolates taken from the Lenawee County site were collected from three tees located at distal corners on the course. Between 60 and 70 samples were taken during each collection from these courses (Table 2). 
Additional S. homoeocarpa isolates were collected on single occasions from additional sites to gain insight into the variation of VCGs across locations in Michigan and from a single site in northern Wisconsin. Collection dates and number of isolates recovered are provided in Table 3.

Isolate recovery. Dollar spots were sampled by collecting infected blades exhibiting advancing disease margins. Infected blades were plated onto acidified water agar ( $24 \mathrm{~g}$ of agar per liter with 10 $\mathrm{ml}$ of lactic acid) and incubated for 2 days at $26^{\circ} \mathrm{C}$. One $S$. homoeocarpa isolate from infected turf recovered from each dollar spot was transferred to potato dextrose agar (PDA; Difco, Detroit, MI). Each isolate was placed in long-term storage by transferring $104-\mathrm{mm}$ plugs into a $1.5-\mathrm{ml}$ microfuge tube with $1 \mathrm{ml}$ of sterile mineral oil and storing at room temperature.
Vegetative compatibility testing. Vegetative compatibility testing was performed by transferring 4-mm-diameter plugs of $S$. homoeocarpa from PDA culture to plates of PDA containing red food color (10 drops per liter of PDA; McCormick and Co., Inc., Hunt Valley, MD) (15). Plates were incubated at $26^{\circ} \mathrm{C}$ for 1 week prior to analysis. Isolates were scored as incompatible if a barrage zone (21) was observed upon inspection of the plate from the top or bottom (Fig. 1). Based on microscopic observations, isolates were determined to be incompatible if abundant aerial mycelia formed along the border of neighboring colonies.

Screening of large collections of isolates recovered from a single sampling date for compatibility was conducted by plating 10 different isolates on an agar plate. Plugs were placed $3 \mathrm{~cm}$ apart on $100 \times 15 \mathrm{~mm}$ petri plates so that each isolate was equidistant from the others. Additional plates were prepared until each of the isolates was plated three times so they were neighboring different isolates on each plate. After 1 week of incubation, plates were scored for compatibility, and compatible isolates were pooled into compatibility groups. These groups and isolates not identified as compatible to other isolates were then plated against isolates belonging to different compatibility pools. All isolates were either placed into VCGs or were found to be incompatible with all other isolates collected. Two isolates from each pooled group were then paired against tester isolates representative of identified VCGs.

Microscopic examination of compatible and incompatible responses was conducted for select isolates to assure that plate reac-

Table 1. Vegetative compatibility groups (VCGs) from dollar spots recovered from the Hancock Turfgrass Research Center (East Lansing, MI)

\begin{tabular}{|c|c|c|c|c|c|c|c|c|}
\hline Year & Collection date $^{a}$ & No. of isolates ${ }^{b}$ & $\begin{array}{c}\mathbf{V C G} \\
\mathbf{A}^{\mathbf{c}}\end{array}$ & $\begin{array}{c}\text { VCG } \\
\text { B }\end{array}$ & $\begin{array}{c}\text { VCG } \\
\mathbf{C}\end{array}$ & $\begin{array}{c}\text { VCG } \\
\text { D }\end{array}$ & $\begin{array}{c}\text { VCG } \\
\mathbf{E}\end{array}$ & $\begin{array}{c}\text { VCG } \\
\mathbf{F}\end{array}$ \\
\hline \multirow[t]{4}{*}{1995} & $6-16$ & 47 & $83 \%$ & $17 \%$ & - & - & - & - \\
\hline & $7-21$ & 50 & $64 \%$ & $36 \%$ & - & - & - & - \\
\hline & $8-30$ & 47 & $43 \%$ & $19 \%$ & $38 \%$ & - & - & - \\
\hline & $9-20$ & 50 & $36 \%$ & $32 \%$ & $22 \%$ & - & $2 \%$ & $8 \%$ \\
\hline \multirow[t]{4}{*}{1996} & $6-12$ & 55 & $68 \%$ & $15 \%$ & $13 \%$ & - & $4 \%$ & - \\
\hline & $7-19$ & 54 & $37 \%$ & $31 \%$ & $26 \%$ & - & $6 \%$ & - \\
\hline & $8-21$ & 54 & $52 \%$ & $24 \%$ & $65 \%$ & - & $9 \%$ & $9 \%$ \\
\hline & $9-21$ & 43 & $63 \%$ & $16 \%$ & $7 \%$ & - & $9 \%$ & $5 \%$ \\
\hline \multirow[t]{5}{*}{1997} & $6-26$ & 55 & $84 \%$ & $15 \%$ & - & - & - & $1 \%$ \\
\hline & $7-10$ & 47 & $81 \%$ & $17 \%$ & - & - & - & $2 \%$ \\
\hline & $8-07$ & 54 & $78 \%$ & $19 \%$ & - & - & $3 \%$ & - \\
\hline & $8-21$ & 57 & $74 \%$ & $26 \%$ & - & - & - & - \\
\hline & $9-18$ & 58 & $71 \%$ & $21 \%$ & $5 \%$ & - & $3 \%$ & - \\
\hline
\end{tabular}

a Diseased tissues were collected every 3 weeks in 1995 and 1996 and every 2 weeks in 1997.

b Number of Sclerotinia homoeocarpa isolates collected at the sampling date.

${ }^{\mathrm{c}}$ Percentage of isolates collected at a sampling date that belonged to each VCG.

Table 2. Vegetative compatibility groups (VCGs) from dollar spots recovered from seasonal sampling of sites in northern Illinois and Lenawee County, MI

\begin{tabular}{|c|c|c|c|c|c|c|c|c|c|}
\hline Year & Site & $\begin{array}{c}\text { Collection } \\
\text { date }^{\mathrm{a}}\end{array}$ & $\begin{array}{l}\text { No. of iso- } \\
\text { lates }\end{array}$ & $\begin{array}{c}\mathbf{V C G} \\
\mathbf{A}^{\mathbf{c}}\end{array}$ & $\begin{array}{c}\text { VCG } \\
\text { B }\end{array}$ & $\begin{array}{l}\text { VCG } \\
\text { C }\end{array}$ & $\begin{array}{c}\text { VCG } \\
\text { D }\end{array}$ & $\underset{\mathbf{E}}{\text { VCG }}$ & $\begin{array}{c}\text { VCG } \\
\mathbf{F}\end{array}$ \\
\hline \multirow{2}{*}{1996} & Illinois & $7-03$ & 47 & $51 \%$ & $45 \%$ & - & $4 \%$ & - & - \\
\hline & & $9-13$ & 57 & $60 \%$ & $37 \%$ & - & $3 \%$ & - & - \\
\hline \multirow[t]{5}{*}{1997} & Illinois & $7-09$ & 50 & $60 \%$ & $40 \%$ & - & - & - & - \\
\hline & & $9-13$ & 33 & - & $82 \%$ & $18 \%$ & - & - & - \\
\hline & Lenawee & $7-05$ & 57 & $51 \%$ & $23 \%$ & - & - & $26 \%$ & - \\
\hline & & $8-24$ & 60 & $43 \%$ & $33 \%$ & - & - & $13 \%$ & $11 \%$ \\
\hline & & $8-27$ & 51 & $35 \%$ & $31 \%$ & - & - & $14 \%$ & $20 \%$ \\
\hline
\end{tabular}

${ }^{\mathrm{a}}$ Diseased tissues were collected once each during early- and late-summer dollar spot epidemics.

${ }^{\mathrm{b}}$ Number of Sclerotinia homoeocarpa isolates collected at the sampling date.

${ }^{\mathrm{c}}$ Percentage of the isolates collected at a sampling date that belonged to each VCG.

Table 3. Vegetative compatibility groups (VCGs) from dollar spots recovered at single sampling of sites in Lenawee, Oscoda, Ingham, Macomb, and Oakland counties in Michigan and a site in northern Wisconsin

\begin{tabular}{|c|c|c|c|c|c|c|c|c|}
\hline Year & Collection site/date & $\begin{array}{l}\text { No. of iso- } \\
\text { lates }^{\mathrm{a}}\end{array}$ & $\begin{array}{c}\mathbf{V C G} \\
\mathbf{A}^{\mathbf{b}}\end{array}$ & $\begin{array}{c}\text { VCG } \\
\text { B }\end{array}$ & $\begin{array}{c}\text { VCG } \\
\mathbf{C}\end{array}$ & $\begin{array}{c}\text { VCG } \\
\text { D }\end{array}$ & $\begin{array}{c}\text { VCG } \\
\mathbf{E}\end{array}$ & $\begin{array}{c}\text { VCG } \\
\text { F }\end{array}$ \\
\hline \multirow[t]{2}{*}{1995} & Lenawee /8-22 & 50 & $58 \%$ & $14 \%$ & - & - & $8 \%$ & $6 \%$ \\
\hline & Oscoda /7-6 & 50 & - & - & $82 \%$ & $18 \%$ & - & - \\
\hline \multirow[t]{3}{*}{1996} & Ingham /8-24 & 60 & $41 \%$ & $25 \%$ & - & - & $27 \%$ & $7 \%$ \\
\hline & Macomb /8-21 & 59 & $54 \%$ & - & $37 \%$ & - & - & $8 \%$ \\
\hline & Oakland /9-13 & 44 & $98 \%$ & - & $2 \%$ & - & - & - \\
\hline 1997 & Wisconsin /8-27 & 43 & $100 \%$ & - & - & - & - & - \\
\hline
\end{tabular}

a Number of Sclerotinia homoeocarpa isolates collected at the sampling date.

${ }^{b}$ Percentage of isolates collected at a sampling date that belonged to each VCG. 
tions corresponded to hyphal interactions. Slides for microscopic examination were prepared by placing $100 \mu \mathrm{l}$ of PDA on a sterile glass slide and covering the PDA with a sterile coverslip. S. homoeocarpa plugs were placed on either side of the coverslip, and the slide was incubated in a sterile petri plate for $48 \mathrm{~h}$. Slides were stained with lactophenol blue and observed with a compound microscope.

Nuclear internal transcribed spacer region 1 sequence analysis. In order to determine if the VCGs identified belong to the same species or if they represent different species, nuclear internal transcribed spacer region 1 (ITS1) sequences from two isolates (isolated from different locations) from each compatibility group were amplified and sequenced. Mycelium was cultivated in $50 \mathrm{ml}$ of malt extract broth $(10 \mathrm{~g}$ of malt extract and $5 \mathrm{~g}$ of glucose per liter) for 1 week at room temperature. Alternatively, aerial mycelium was harvested directly from PDA plates incubated in an inverted position. DNA was extracted following a modified protocol of Lee and Taylor (18). Modifications to the protocol were necessary due to the high levels of polysaccharides produced by $S$. homoeocarpa in culture. Enough mycelia were placed into a $1.5-\mathrm{ml}$ microfuge tube to fill to the $0.25-\mathrm{ml}$ mark along with $500 \mu \mathrm{l}$ of lysis buffer $(50 \mathrm{mM}$ Tris- $\mathrm{HCl}, \mathrm{pH} 7.2,50$ $\mathrm{mM}$ EDTA, and $3 \%$ sodium dodecyl sulfate [SDS]) and homogenized with a Teflon tissue grinder. Tubes were incubated at $65^{\circ} \mathrm{C}$ for $1 \mathrm{~h}$. Seven hundred microliters of chloroform:phenol $(1: 1 ; \mathrm{vol} / \mathrm{vol})$ was added, and the tubes were vortexed and centrifuged for $5 \mathrm{~min}$. The aqueous phase was transferred to a new microfuge tube along with $700 \mu \mathrm{l}$ of chloroform:isoamyl alcohol (24:1; vol/vol). Following mixing and centrifugation, the aqueous phase was transferred to a clean $1.5-\mathrm{ml}$ tube containing $50 \mu \mathrm{l}$ of $3 \mathrm{M}$ sodium acetate. DNA was precipitated with isopropanol and refrigerated overnight. Final DNA recovery consisted of pelleting of DNA by centrifugation for 5 min, washing of the pellet with 1 $\mathrm{ml}$ of $95 \%$ ethanol, removal of the supernatant, and drying under a vacuum. DNA pellets were then resuspended in $100 \mu \mathrm{l}$ of TE buffer.

ITS1 sequences were amplified using the ITS1 (TCCGTAGGTGAACCTGCGG) and ITS2 (GCTGCGTTCTTCATCGATGC) primers of White et al. (29). PCR reactions were carried out following the thermal protocol of Carbone and Kohn (3): (i) $93^{\circ} \mathrm{C}, 1 \mathrm{~min}$; (ii) $40^{\circ} \mathrm{C}, 1 \mathrm{~min}$; (iii) $62^{\circ} \mathrm{C}$, $10 \mathrm{~s}$; (iv) increase $9^{\circ} \mathrm{C}$ at rate of $1^{\circ} \mathrm{C}$ every $5 \mathrm{~s}$; (v) $71^{\circ} \mathrm{C}, 1 \mathrm{~min}$; (vi) $93^{\circ} \mathrm{C}, 1 \mathrm{~min}$; (vii) cycle to step 2,24 times; (viii) $40^{\circ} \mathrm{C}, 1$ min; (ix) $62^{\circ} \mathrm{C}, 10 \mathrm{~s}$; (x) increase $9^{\circ} \mathrm{C}$ at rate of $1{ }^{\circ} \mathrm{C}$ every $5 \mathrm{~s}$; (xi) $71^{\circ} \mathrm{C}, 5 \mathrm{~min}$; (xii) $4^{\circ} \mathrm{C}$, hold. PCR products were purified with the Wizard PCR Purification prep kit (Promega, Madison, WI). Sequencing of PCR products was performed at the
MSU DNA sequencing facility (Michigan reactions were performed using each of the primers used to amplify the ITS1 region. Resulting sequences were aligned using the SeqEdit program (Perkin Elmer, Norwalk, CT, 1996) to assure sequence integrity.

\section{RESULTS}

All but a few of the infected turf samples collected from dollar spots yielded $S$. homoeocarpa isolates on acidified water agar. S. homoeocarpa isolates were easily recovered from acidified water agar as tufts of aerial mycelium following 2 days of incubation. Mycelial growth on PDA was generally rapid, covering the plate within $48 \mathrm{~h}$, and varied from dense cottony to supinate growth on the agar surface. A few isolates recovered from infected turf grew slowly on PDA with sparse mycelial growth. These isolates were recovered during sampling of both epidemics. The mycelia of these isolates were brown in color and released a brown pigment into the media. Occasionally a sector that exhibited growth typical of $S$. homoeocarpa developed from these restricted-growth isolates.

Vegetative compatibility reactions were easily scored following 1 week of incubation on media amended with red food color. Incompatible reactions were identified by barrage zone formation and dense aerial mycelia along colony borders (Fig. 1). Grouping of isolates from a single collection date into VCGs usually required three rounds of platings. Isolates exhibiting sparse growth that did not sector into a more typical growth habit were not scored for compatibility because they were rapidly overgrown by typical strains of $S$. homoeocarpa and compatibility reactions were not clearly identifiable. Compatibility reactions on the food color-amended PDA State University, East Lansing). Sequence

were supported by microscopic observations (data not shown). Compatible hyphal anastomoses showed similar staining and cellular inclusions to typical cells. Incompatible anastomoses retained less stain and exhibited disorganization of cell inclusions.

Seasonal variation among $S$. homoeocarpa isolates. $S$. homoeocarpa vegetative compatibility data from season-long sampling at the HTRC for 1995, 1996, and 1997 resulted in identification of six VCGs (Table 1). The first two samplings in 1995 were collected during the early summer dollar spot epidemic. Isolates collected on these dates belonged to VCGs A and B and were recovered at a ratio of roughly $2: 1$. At the 30 August 1995 sampling, in addition to VCGs A and B, isolates were recovered belonging to VCG C. The ratio of VCG A to $\mathrm{B}$ isolates remained similar (2:1); VCG $\mathrm{C}$ was isolated at a similar frequency as VCG A. Two additional VCGs, E and F, were identified only in the final sampling date of 20 September 1995.

Isolates of $S$. homoeocarpa recovered during the early summer epidemic of 1996 belonged to VCG A, B, C, and E (Table 1). VCG A was the predominant group recovered at the first sampling in June, but was roughly equal to groups $\mathrm{B}$ and $\mathrm{C}$ in July. The same VCGs were recovered in August and September, with the addition of VCG $\mathrm{F}$, and VCG A being the most predominant group during this season. VCG A and B were recovered during all sampling dates of 1997, with group A being the most predominant group. Group F was recovered at a low frequency during sampling in June and July. Through August and September, VCG $\mathrm{C}$ and $\mathrm{E}$ were recovered at low levels, with VCG A and B remaining the predominant groups.

Six VCGs also were recovered from seasonal sampling at locations in northern

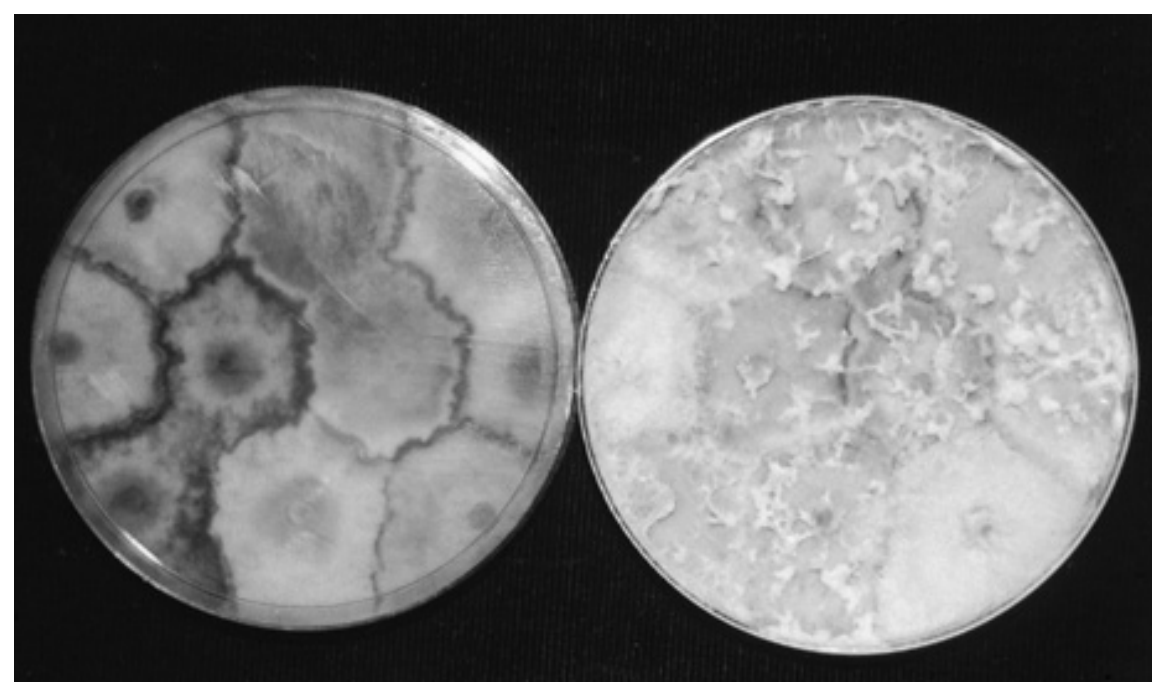

Fig. 1. Vegetative interactions among Sclerotinia homoeocarpa isolates on potato dextrose agar amended with red food color after 1 week of incubation. The plate on the left shows the bottom of the petri plate and demonstrates the barrage zones typical of incompatible reactions between isolates. The plate on the right shows the sample isolates as viewed from the top of the plate. 
Illinois and Lenawee County, MI (Table 2). One site in northern Illinois was sampled during seasonal epidemics in 1996 and 1997. In the early summer of 1996 (3 July), the $S$. homoeocarpa isolates recovered belonged to VCG A, B, and D. The same VCGs were recovered in a second sampling on 13 September 1996. However, in the early summer (9 July) of 1997, only isolates belonging to VCG A and B were recovered. A change in the population recovered was noted in the late summer (13 September 1997) as isolates belonging to VCG A were not recovered. VCG B was the most common VCG recovered, and a few isolates of VCG $\mathrm{C}$ were recovered from this site for the first time.

A site in Lenawee County was sampled during the seasonal epidemics in 1997. The first sampling (5 July 1997) recovered isolates belonging to VCG A, B, and $\mathrm{E}$. These same VCGs were recovered in the late summer epidemic (24 August 1997), with the addition of VCG F. A second sampling at the same location taken 3 days later revealed a ratio of VCGs which was not different from the previous sampling 3 days earlier when compared by chi-square analysis $(P \leq 0.05)$, with a chi-square distribution value of $P=0.52$.

Several sites were sampled on single occasions to determine if additional VCGs could be identified (Table 3). In 1995, VCGs A, B, E, and F were recovered from the Lenawee County site in August. These same VCGs were recovered in the August sampling of 1997 (Table 2) at the same site. S. homoeocarpa isolates of VCG C and D were recovered in Oscoda County, MI. Three additional sites were sampled on one occasion in 1996. A site in Ingham County, MI, yielded isolates representative of VCG A, B, E, and F. Two sites in Oakland and Macomb counties in Michigan yielded isolates belonging to VCG A and C. Of these, only one isolate of the 44 collected from the site in Oakland County belonged to VCG C. S. homoeocarpa isolates sampled in 1997 from northern Wisconsin all belonged to VCG A.

ITS1 analysis. Amplification of the ITS1 region was conducted using representative isolates of each of the VCGs isolated (A to F). Each of the isolates yielded an ITS1 fragment of 212 base pairs. Comparison of the resulting sequences identified a single sequence shared by all of the isolates sequenced. This sequence is identical to the ITS1 sequence reported for S. homoeocarpa by Carbone and Kohn (3).

\section{DISCUSSION}

The results of this study suggest that seasonal dollar spot epidemics are the result of a single species rather than being caused by multiple species. Examination of isolates throughout the season identified six VCGs that were common to locations sampled in Michigan, Illinois, and Wiscon- sin. Each VCG identified was recovered during both of the seasonal dollar spot epidemics. Sequencing of the ITS1 region of isolates representative of each VCG yielded a conserved sequence of 212 base pairs, indicating that the VCGs identified here represent diversity within a single species rather than representing multiple species.

The isolate recovery procedure used in this study did not preclude the potential of a bias toward recovery of certain VCGs from infected blades. Isolates were recovered from infected blades from single dollar spots by transferring a single isolate from an infected blade to PDA. It is possible that slower growing strains of $S$. homoeocarpa could have been present in different blades from the same dollar spot that were either not recovered by this recovery technique or were not selected in favor of faster growing strains.

The majority of isolates collected exhibited the typical cultural characteristics of $S$. homoeocarpa. Several isolates exhibited a sparse growth habit in culture that was similar to that of hypovirulent $S$. homoeocarpa isolates containing dsRNA (31). Further support of this is the fact that these isolates would occasionally produce sectors of growth typical of S. homoeocarpa.

Five VCGs were recovered from bi- and triweekly sampling of dollar spot from the HTRC at Michigan State University. VCG $\mathrm{A}$ and $\mathrm{B}$ were recovered at all sampling dates throughout the 3 years of the study. VCG $\mathrm{C}$ and $\mathrm{E}$ were first recovered in the late summer of 1995 and throughout the year in 1996 and on two dates in 1997. They may have been present throughout 1997 at levels beyond detection of the sampling scheme employed. Isolates belonging to VCG F were only recovered during the late summer epidemics of 1995 and 1996, suggesting that they may be specific to the fall epidemic. However, in 1997, VCG F was only recovered during the early summer epidemic.

Similar results were observed from isolates collected during early and late summer epidemics at locations in northern Illinois and Lenawee County in southern Michigan. In 1996, VCGs at the northern Illinois location were recovered at similar levels during the early and late epidemics. During 1997, there was a significant shift in the population, with VCG D not being recovered at either sampling date. The late epidemic of the year also reflected the loss of VCG A and development of VCG C. The reason for the large shift in the VCGs recovered is uncertain but may be tied to the low levels of disease that had developed up to the time of the fall collection date. The site in Lenawee County shared a VCG profile similar to that of the HTRC in 1995 and 1996. VCG F was only recovered during the late summer epidemic, as was found at the HTRC in previous years, fur- ther suggesting a seasonal bias to late summer epidemics. However, in 1997, VCG F was found in the early summer at the HTRC of Michigan State University. The reason for this difference is uncertain but may be attributed to local environmental differences associated with the unusually cool spring in 1997.

Collections of $S$. homoeocarpa isolates from six additional locations gave additional evidence that there is limited diversity among VCGs of $S$. homoeocarpa in Michigan. All isolates collected from these additional locations were accommodated within the six VCGs described. Two locations of special interest were those in Oakland County, MI, and northern Wisconsin. The site sampled in Oakland County has been identified as having $S$. homoeocarpa populations resistant to the demethylase inhibitor fungicides. All but one of the isolates from this site belonged to VCG A. While fungicide resistance levels were not determined for these isolates, it is suggestive of a shift in the population toward a clonal lineage that expresses fungicide resistance. The other site of interest is the site from Wisconsin, of which all of the isolates belonged to VCG A. This golf course was established in 1995, and isolation of only a single VCG suggests that an isolate of this VCG was introduced to this site and is responsible for dollar spot at this location.

The limited number of VCGs recovered in this study is similar to work with the asexual pathogen Fusarium oxysporum f. sp. melonis (12). VCG A was the most commonly recovered VCG, being recovered from eight of the nine locations sampled, and was the most frequently recovered VCG at each of these locations. Whereas the production of apothecia by $S$. homoeocarpa has been reported to occur in British isolates $(1,11)$, production of fertile apothecia has not been identified in the United States $(2,7,11)$. Limitations on the number of VCGs identified will depend on the rate of migration, loss of VCGs among asexual populations due to genetic drift, and the lack of sexual recombination of the loci that are responsible for vegetative incompatibility (19).

The limited diversity among VCGs recovered in this study contrasts with the study by Sonoda that identified 16, 20, and 19 VCGs among collections of 35, 37, and 47 isolates, respectively, representing three different locations in Florida (25). The greater diversity among VCGs identified by Sonoda could be the result of greater diversity of host grasses cultivated or the possibility of sexual recombination among $S$. homoeocarpa isolates. A direct comparison of isolates collected in this study with the isolates collected by Sonoda from Paspalum notatum would yield additional insight into the relationship between these populations.

The identification of a limited number of VCGs raises the potential of using vegeta- 
tive compatibility for further studies on $S$. homoeocarpa. The limited numbers of VCGs increases the likelihood that biological control strategies making use of hypovirulent strains of $S$. homoeocarpa (31) would be successful. Population studies may make use of the introduction of a VCG into an area where it had not been previously identified to track the introduced isolate over time. This may include studies tracking the spread of $S$. homoeocarpa isolates at a single location over time, the overwintering capabilities of $S$. homoeocarpa, and whether dollar spots arise in the same location during different seasons from the same inoculum source. Further questions also remain about potential differences among VCGs with respect to virulence, temperature optima, and fungicide sensitivity.

\section{ACKNOWLEDGMENTS}

We thank Dan Dinelli and Fred Powell for their help collecting dollar spot isolates from locations in Illinois and Lenawee County, MI. Additional thanks go to Ron Detweiler, Nancy Dykema, and Daniel McMahon for additional help collecting isolates.

\section{LITERATURE CITED}

1. Baldwin, N. A., and Newell, A. J. 1992. Field production of fertile apothecia by Sclerotinia homoeoecarpa in Festuca turf. J. Sports Turf Res. Inst. 68:73-76.

2. Bennett, F. T. 1937. Dollar spot disease of turf and its causal organism Sclerotinia homoeocarpa n. sp. Ann. Appl. Biol. 24:236-257.

3. Carbone, I., and Kohn, L. M. 1993. Ribosomal DNA sequence divergence within internal transcribed spacer 1 of the Sclerotiniaceae. Mycologia 85:415-427.

4. Couch, H. B., and Bloom, J. R. 1960. Influence of environment on diseases of turfgrasses. II. Effect of nutrition, $\mathrm{pH}$, and soil moisture on Sclerotinia dollar spot. Phytopathology 50:761-763.

5. Detweiler, A. R., Vargas, J. M., Jr., and Danneberger, T. K. 1983. Resistance of Sclerotinia homoeocarpa to iprodione and benomyl. Plant Dis. 67:627-630.

6. Dobinson, D. F., Patterson, N. A., White, G. J., and Grant, S. 1998. DNA fingerprinting and vegetative compatibility analysis indicate multiple origins for Verticillium dahliae race 2 tomato isolates from Ontario, Canada. Mycol. Res. 102:1089-1095.

7. Fenstermacher, J. M. 1979. Certain features of dollar spot disease and its causal organism, Sclerotinia homoeoecarpa. Pages 49-58 in: Advances in Turfgrass Pathology. B. G. Joyner and P. O. Larsen, eds. Harcourt Brace Jovanovich, Duluth, MN.

8. Golembiewski, R. C., Vargas, J. M., Jr., Jones, A. L., and Detweiler, A. R. 1995. Detection of demethylation inhibitor (DMI) resistance in Sclerotinia homoeocarpa populations. Plant Dis. 79:491-493.

9. Goodman, D. M., and Burpee, L. L. 1991. Biological control of dollar spot disease of creeping bentgrass. Phytopathology 81:14381446.

10. Gordon, T. R., and Okamoto, D. 1992. Variation in mitochondrial DNA among vegetatively compatible isolates of Fusarium oxysporum. Exp. Mycol. 16:245-250.

11. Jackson, N. 1973. Apothecial production in Sclerotinia homoeoecarpa F. T. Bennett. J. Sports Turf Res. Inst. 49:58-63.

12. Jacobson, D. J., and Gordon, T. R. 1990. Further investigations of vegetative compatibility within Fusarium oxysporum f. sp. melonis. Can. J. Bot. 68:1245-1248.

13. Jacobson, D. J., and Gordon, T. R. 1991. Fusarium oxysporum f. sp. melonis: A case study of diversity within a forma specialis. Phytopathology 81:1064-1067.

14. Kohn, L. M. 1979. Delimitation of the economically important plant pathogenic Sclerotinia species. Phytopathology 69:881-886.

15. Kohn, L. M., Carbone, I., and Anderson, J. B. 1990. Mycelial interactions in Sclerotinia sclerotiorum. Exp. Mycol. 14:255-267.

16. Kohn, L. M., and Grenville, D. J. 1989. Anatomy and histochemistry of stromatal anamorphs in the Sclerotiniaceae. Can. J. Bot. 67:371-393.

17. Kohn, L. M., Stasovski, E., Carbone, I., Royer, J., and Anderson, J. B. 1991. Mycelial incompatibility and molecular markers identify genetic variability in field populations of Sclerotinia sclerotiorum. Phytopathology 81:480-485.

18. Lee, S., and Taylor, J. 1990. Recovery of DNA from fungi. Pages 282-287 in: PCR Protocols: A Guide to Methods and Applications. M. A. Innis, D. H. Gelfand, J. J. Sninsky, and T. J. White, eds. Academic Press, San Diego, CA.
19. Leslie, J. F. 1993. Fungal vegetative compatibility. Annu. Rev. Phytopathol. 31:127-150.

20. Markland, R. E., Roberts, E. C., and Frederick, L. R. 1969. Influence of nitrogen fertilizers on Washington creeping bentgrass, Agrostis palustris Huds. II. Incidence of dollar spot, Sclerotinia homoeocarpa, infection. Agron. J. 61:701:705.

21. Newhouse, J. R., and MacDonald, W. L. 1991. The ultrastructure of hyphal anastomoses between vegetatively compatible and incompatible virulent and hypovirulent strains of Cryphonectria parasitica. Can. J. Bot. 69:602-614.

22. Novak, L. A., and Kohn, L. M. 1991. Electrophoretic and immunological comparisons of developmentally regulated proteins in members of the Sclerotiniaceae and other sclerotial fungi. Appl. Environ. Microbiol. 57:525-534.

23. Smiley, R. W. 1992. Compendium of Turfgrass Diseases. American Phytopathological Society, St. Paul, MN. pp. 14-15.

24. Smith, J. D., Jackson, N., and Woolhouse, A R. 1989. Fungal Diseases of Amenity Turf Grasses. E. and F. N. Spon, New York.

25. Sonoda, R. M. 1988. Vegetative compatibility groups among Sclerotinia homoeocarpa from leaves of Paspalum notatum. Proc. Soil Crop Sci. Soc. Fla. 48:35-36.

26. Stenlid, J. 1985. Population structure of Heterobasidion annosum as determined by somatic incompatibility, sexual incompatibility, and isozyme patterns. Can. J. Bot. 63:22682272.

27. Vargas, J. M., Jr. 1994. Management of Turfgrass Diseases. Lewis Publishers, Ann Arbor, MI.

28. Warren, C. G., Sanders, P., and Cole, H. 1974. Sclerotinia homoeocarpa tolerance to benzimidazole configuration fungicides. Phytopathology 64:1139-1142.

29. White, T. J., Bruns, T., Lee, S., and Taylor, J. 1990. Amplification and direct sequencing of fungal ribosomal RNA genes for phylogenetics. Pages 315-322 in: PCR Protocols: A Guide to Methods and Applications. M. A. Innis, D. H. Gelfand, J. J. Sninsky, and T. J. White, eds. Academic Press, San Diego, CA.

30. Williams, D. W., Powell, A. J., Jr., Vincelli, P., and Dougherty, C. T. 1996. Dollar spot on bentgrass influenced by displacement of leaf surface moisture, nitrogen and clipping removal. Crop Sci. 36:1304-1309.

31. Zhou, T., and Boland, G. J. 1997. Hypovirulence and double-stranded RNA in Sclerotinia homoeocarpa. Phytopathology 87:147-153. 